amino acid sequence similarities. Comparisons of the peptide sequences within these regions highlight similarities with members of the carmovirus and tombusvirus groups. However, the genome size and predicted strategy seem intermediate between the 2 groups. We propose the name of oat chlorotic stunt for the new virus and suggest that although evolutionarily related to both the tombusviruses and the carmoviruses, it is distinct from both and should therefore not be classified within either group. Epidemiological studies at one of the infected sites have shown that the virus causes mainly root localised infection, and only in a small number of cases does it cause systemic infection. Infection is not limited to oats; although this seems to be the major host, infection is also detected in winter wheat and winter barley.

\section{Some properties of Lolium latent virus.} W Huth, DE Lesemann, R Götz, HJ Vetten (Biological Research Center for Agriculture and Forestry, Institute for Biochemistry and Plant Virology, Messeweg 11/12, D-38104 Braunschweig, Germany)

Lolium latent virus (LLV) was found during investigations on ryegrass mosaic virus (RMV) and hitherto it was only detected on Lolium perenne and $L$ multiflorum collected in breeding stations in Germany and the Netherlands. From a total of 348 virus-infected plants of $L$ perenne $20(6 \%)$ plants were infected exclusively by LLV, 183 $(52 \%)$ by RMV only whereas $145(42 \%)$ plants were dually infected by both viruses, LLV and RMV.

LLV is mechanically transmissible but with crude plant extract in general a low proportion of inoculated plants becomes infected. $L$ multiflorum is more susceptible than $L$ perenne. Whereas infected Lolium spp remain symptomless, the more susceptible Bromus spp, Briza maxima, oat, barley, rye and some other Poaceae reacted with mild streaks on their leaves. On leaves of infected $L$ multiflorum grown in the greenhouse yellow spots were occasionally observed. Unusually for virus diseases these spots appear on old leaves only and led to an earlier senescense of these. Plants of Lolium spp dually infected by LLV and RMV showed reduced growth and intensified RMV symptoms. White streaks on the youngest still rolled leaves are predominant symptoms of dually infected plants.
LLV is also easily transmissible to some dicotyledonous plants. After inoculation on leaves of Gomphrena globosa local lesions with red margins appear. Chenopodium amaranticolor, Nicotiana benthamiana and Tetragonia expansa develop systemic infections. The latter is especially useful as propagation host.

A natural vector of LLV has not yet been found although preliminary transmission studies indicate that Rhopalosiphum padi might very ineffectively transmit the virus to $L$ multiflorum ( 8 of 508 plants became infected).

The flexible particles of LLV have a normal length of ca $640 \mathrm{~nm}$. Their surface structure with cross-banding and longitudinal files resembles that of potexviruses. From foxtail mosaic virus (FMV), the only definite potexvirus of Poaceae, LLV differs in particle length (FMV ca $550 \mathrm{~nm}$ ) and the molecular weights of coat protein (LLV $35 \mathrm{kDa}, \mathrm{FMV} 32 \mathrm{kDa}$ ) and nucleic acid (LLV $2.7 \times 10^{6} \mathrm{kDa}$, FMV $2.1 \times 10^{6} \mathrm{kDa}$ ).

LLV is not serologically related to FMV or to 25 definite or possible members of the potexivirus group as well as to 25 members of the carlavirus group.

Huth W, Lesemann DE, Vetten HJ, Götz R (1995) A new possible potexvirus isolated from Lolium spp. Fourth Int Conf Plant Diseases, Bordeaux 6-8 Dec 1994, vol III/III, 1095-1099

Paulsen AQ, Niblett CL (1977) Purification and properties of foxtail mosaic virus. Phytopathology 67 , 1346-1351

Interaction of BYDV and Fusarium culmorum in winter wheat. $\mathrm{N}$ Koch, W Huth (Federal biological Research Center, Institute for Biochemistry and Plant Virology, Messeweg 11/12, D-38104 Braunschweig, Germany)

Although BYDV is one of the most common pathogens of cereals in Germany, epidemics of this virus have been very rare. Nevertheless there was a serious outbreak over 3 years from 1988-1990 and it was not barley but mainly wheat which reacted with strong symptom expression upon infection (Huth, 1990). In some regions reddening of flag leaves, the most prominent symptom of BYDV infection of wheat, was found on most of the plants; surprisingly the latesown wheat was much more affected than the early-sown one.

During these epidemic wheat was infected at late growth stages from May to July. Nevertheless in some fields yield reductions over 